\title{
Synthesis of silica of rice husk modification (3-aminopropyl) trietoxysilane for adsorption methylene blue
}

\author{
Yusmaniar Yusmaniar ${ }^{1}$, Darsef Darwis ${ }^{1}$, Afrizal Afrizal ${ }^{1}$, and Annisa Annisa ${ }^{1}$ \\ ${ }^{1}$ Universitas Negeri Jakarta, Fakultas Matematika dan Ilmu pengetahuan Alam, Departemen Kimia, Jln. Rawamangun Muka Jakarta \\ 13220
}

\begin{abstract}
In this study, modified silica (3-Amynopropyl) triethoxysilane (APTES) synthesis and adsorption test of MB dye were performed. Silica is synthesized by sol-gel method and modified with APTES. APTES modified silica is characterized using several instruments, scanning electron microscopy (SEM), fourier transform infrared (FTIR), surface area analyzer (SAA) and UV-Vis spectrophotometer. The composite has a large surface area and has a mesoporous shape. At alkaline $\mathrm{pH}, \mathrm{MB}$ dye can adsorb well. In addition, MB absorption is also maximized with the longer time of adsorption. The APTES modified silica adsorption process follows the Langmuir isotherm pattern. Thus, APTES modified silica can be used as an alternative to environmentally friendly and low-cost adsorbents.
\end{abstract}

\section{Introduction}

Environmental pollution is one of the problems facing the society lately. This pollution occurs in various types. Among them is, disposal of industrial waste into the aquatic environment [1]. In industrial waste contains compounds or elements that can endanger the biota and the environment around the water. Organic dyes are one of the compounds contained in industrial waste[2]. The nature of this organic dye is difficult to decompose by microorganisms because of its complex structure and difficult to separate from water [3]. One of the organic dyes is Methylene Blue. MB is a thiazine dye that can have harmful effects, such as can cause heart rate be quick, shock, nausea, vomiting and others [4-8]

Various studies have been conducted to reduce the pollution of substances organic colors in waters by chemical or physical methods. Among them are, coagulation / flocculation [9], membrane separation [10] and adsorption [11]. The method of adsorption is one method that can be done in reducing pollution in the aquatic environment. The adsorbent used should have pore size, pore distribution and surface area $[12,13]$. One of the adsorbents that can be used for adsorption of organic dyes is silica. Silica itself can be found in nature, such as in husks rice. Where rice husk contains silica as much as $87-97 \%$ dry weight [14]. The silica was synthesized using a sol-gel method then modified with an organic functional group aimed at enhancing the adsorption ability [15].

\section{Methods}

Rice husk that has become charcoal is burned to ashes. Rice husk ash is added with $6 \mathrm{M} \mathrm{HCl}$ then refluxed. After reflux, the mixture is washed with $\mathrm{DM}$ aqua until it is lost of acidic properties. Then the mixture was added $1 \mathrm{M}$ $\mathrm{NaOH}$ and refluxed again. The result of reflux is filtered and washed with hot DM aqua, then filtrate of the filtered product with $1 \mathrm{M} \mathrm{HCl}$ to form gel at neutral $\mathrm{pH}$. The formed gel is washed with aqua DM to $\mathrm{Cl}$-free. $\mathrm{Gel}$ that is free from $\mathrm{Cl}$ - is then dried. The formed silica was then suspended in toluene and added a silane (3aminopropyl) triethoxysilane (APTES) and refluxed coupling agent [16].

Methylene Blue solution with a concentration of 10 ppm was prepared under $\mathrm{pH}$ conditions 3, 5, 7, 8 and 10 . Then add modified silica APTES and shaken at $180 \mathrm{rpm}$ for 30 minutes. Methylene Blue solution with $10 \mathrm{ppm}$ concentration of APTES modified silica was then shaken at $180 \mathrm{rpm}$ for $10,20,30,40,50,60 \mathrm{~min}$.

Methylene Blue solution was made with various concentrations of $30,60,90,120$ and $150 \mathrm{ppm}$ at $\mathrm{pH}$ conditions and optimum contact time. Then APTES modified silica was then shaken at $180 \mathrm{rpm}$.

\section{Results and discussion}

Silica and silica-APTES that have been formed are then characterized using several instruments. In Fig. 1 is a morphological form of silica of synthesis and silica that has been modified using SEM (Scanning Electron Microscopy) instrument. From the figure it can be seen that at magnification 500 particle size of modified silica APTES $20 \mu \mathrm{m}$. Whereas silica has particle size $50 \mu \mathrm{m}$.

\footnotetext{
Corresponding author: yusmaniar@unj.ac.id
} 


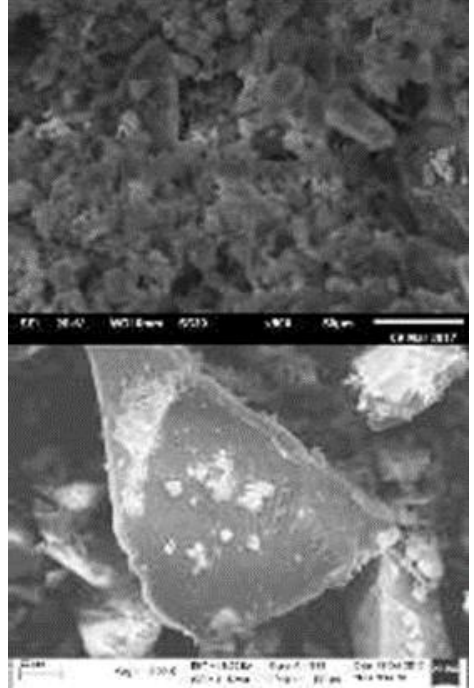

Fig. 1. SEM image silica and silica-APTES.

Based on fig.1, the APTES modified silica particle size is smaller than that of silica. In addition to its changing size, the silica-particles and silica-APTES are different. In silica the form of the particles is uniform while on the silica-APTES the particle shape is bulk and not uniform

In addition to morphology, the constituents in silica and silica-APTES also differ. This can be known through EDX instruments (Electron Dispersive X-Ray). In silica there are only $\mathrm{Si}$ and $\mathrm{O}$ elements, whereas in silica-APTES it is seen that new elements are increasing, ie $\mathrm{N}$ and $\mathrm{C}$. The addition of these elements is assumed to be derived from APTES used.

Table 1. Silica and Silica-APTES Composition.

\begin{tabular}{|c|c|c|}
\hline \multirow{2}{*}{ Element } & Silica & $\begin{array}{c}\text { Silica- } \\
\text { APTES }\end{array}$ \\
\cline { 2 - 3 } & \multicolumn{2}{|c|}{ Mass (\%) } \\
\hline Silicon (Si) & 44,85 & 27,44 \\
\hline Oxygen (O) & 55,15 & 43,69 \\
\hline Nitrogen (N) & - & 3,45 \\
\hline Carbon $(\mathrm{C})$ & - & 25,21 \\
\hline
\end{tabular}

In addition to SEM-EDX, silica and silica-APTES instruments are also characterized using FTIR. The spectral form of silica and silica-APTES can be seen in Figure 2. The absorption bands at wavelengths 790.81 $\mathrm{cm}^{-1}$ and $968.27 \mathrm{~cm}^{-1}$ are vibrations of Si-O symmetric $\mathrm{Si}-\mathrm{O}-\mathrm{Si}$ and vibration of Si-O Si-O from $\mathrm{Si}-\mathrm{OH}$. While the strong absorption bands occur at a wavelength of $1091.71 \mathrm{~cm}^{-1}$ which is a symmetrical vibration of $\mathrm{Si}-\mathrm{O}$ from Si-O-Si. The absorption bands at wavelengths of $1639.49 \mathrm{~cm}^{-1}$ and $3340.71 \mathrm{~cm}^{-1}$ are vibrations of Si-OH buckling and symmetrical vibration of $\mathrm{OH}-\mathrm{Si}-\mathrm{OH}$.

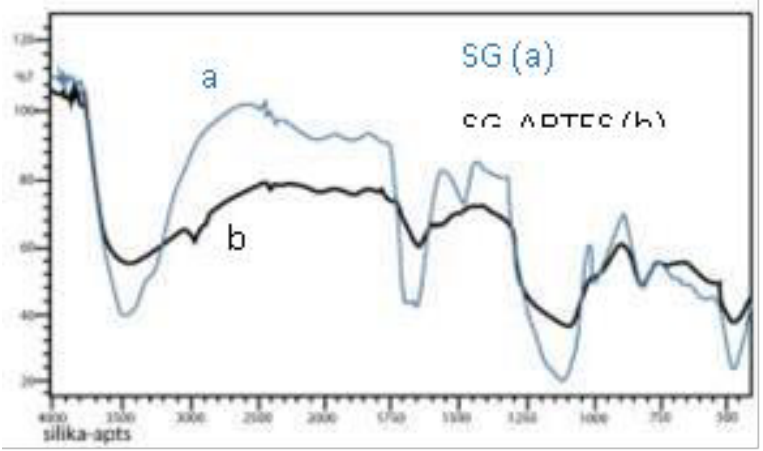

Fig. 2. FTIR Spectrum of silica and silica APTES.

The absorption bands at wavelengths $968.27 \mathrm{~cm}^{-1}$ as seen on silica, now on silica APTES already lost. This shows that silica-APTES does not contain $\mathrm{Si}-\mathrm{O}$ from $\mathrm{Si}$ $\mathrm{OH}$. In addition, in silica-APTES a decrease of absorbing band $3423.65 \mathrm{~cm}^{-1}$ indicates secondary $\mathrm{N}-\mathrm{H}$ bending vibration and the emergence of new bands at $2926.01 \mathrm{~cm}^{-1}$ indicates the presence of aliphatic chains due to vibration - $\mathrm{CH} 2$-so that APTES modified silica has been successfully established. Based on Fig. 3, the silicasilica-APTES adsorption-desorption and silica pattern follow type IV indicating that the pore shape is mesoporous. This mesoporous form is seen on the $\mathrm{P} / \mathrm{Po}$ curve above 0.5 .

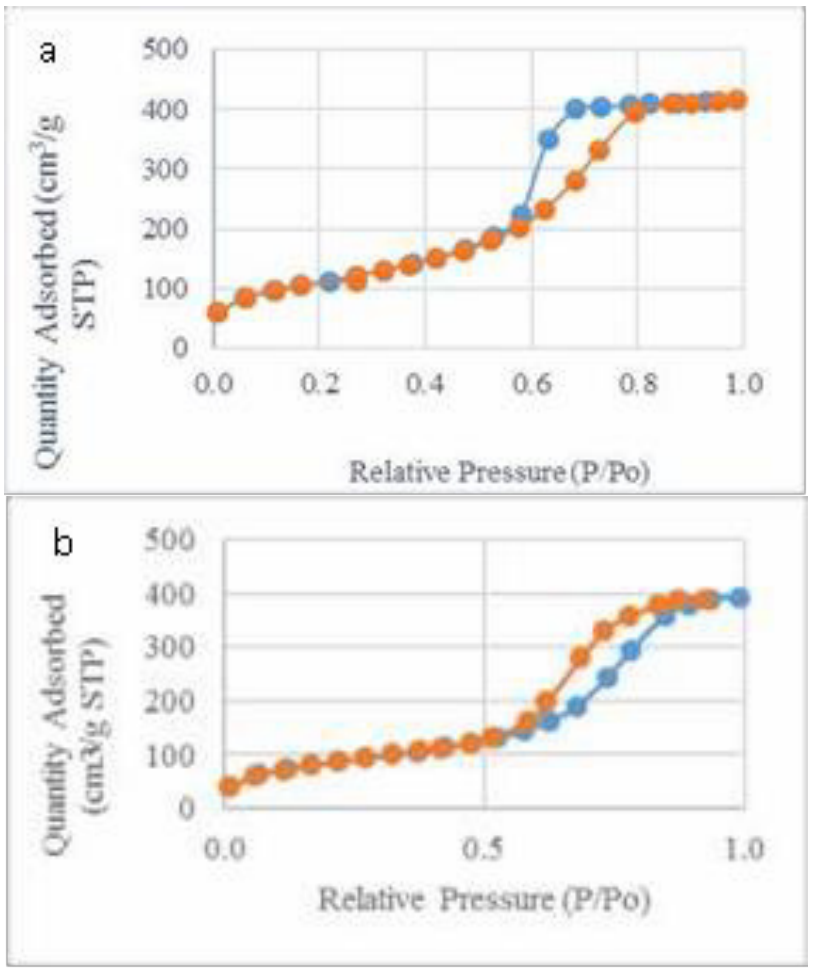

Fig. 3. BET Result of silica and silica APTES.

\subsection{Adjustable silica adsorption test of APTES effect of $\mathrm{pH}$}

The $\mathrm{pH}$ value can affect the adsorption process. Where will the charge distribution occur on the adsorbent due to the reaction of protonation and deprotonation on the active adsorbent site. In figure 4 it can be seen that with 
increasing $\mathrm{pH}$, the absorption of $\mathrm{MB}$ dye will be greater. In the highest absorption silica occurs at $\mathrm{pH} 8$ with an adsorption capacity of $5.688 \mathrm{mg} / \mathrm{g}$ as well as silicaAPTES most absorption occurs at $\mathrm{pH} 8$ also with an adsorption capacity of $5.815 \mathrm{mg} / \mathrm{g}$. This is because the alkaline $\mathrm{pH}$ causes the hydroxyl group to increase and will attract the cluster $\mathrm{N}+$ on the $\mathrm{MB}$ compound.

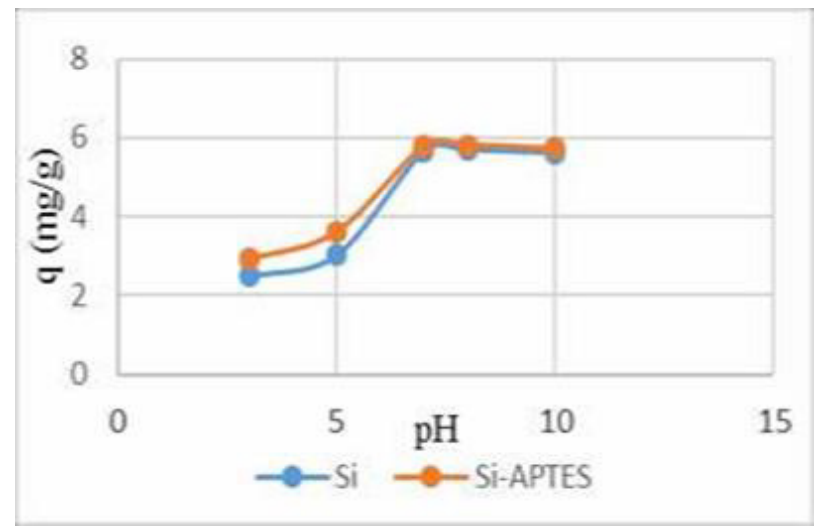

Fig. 4. Effect of initial $\mathrm{pH}$ value on the adsorption capacity.

\subsection{Influence of contact time}

The contact time may also affect the adsorption process. Where the longer the adsorption time the adsorption molecule absorption will last better until it reaches a stable state. Because the longer the adsorption molecule adsorption molecules will be maximally absorbed in the adsorbent so that the empty space in the adsorbent is fully charged.

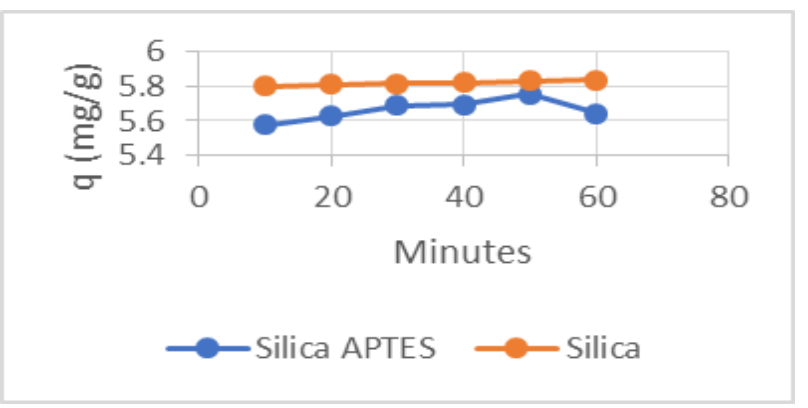

Fig. 5. Effect of contact time on MB removal.

In figure 5, it can be seen that silica and silicaAPTES capabilities have a time difference in absorbing MB dye. In silica, 50 minutes is the maximum absorption with an adsorption capacity of $5.755 \mathrm{mg} / \mathrm{g}$ and at 60 minutes the capacity assumes that the adsorbent has a heterogeneous surface and each molecule has different absorption potentials. The formula in determining Freundlich isotherm is: adsorption down. mIt this because silica adsorbent is in saturation state or can no longer absorb MB dye while in silica-APTES the longer its adsorption capacity is 5,831 $\mathrm{mg} / \mathrm{g}$. This is because the increase of functional groups on silica-APTES causes silica-APTES to take longer to absorb MB dye until it reaches equilibrium.

\subsection{Isotherm model}

Isotherm Langmuir introduces the concept of monomolecular adsorption on a homogeneous surface. The adsorbent which is a Langmuir isotherm has a fixed place, absorbing one molecule and forming a monolayer. The formula used in determining the Langmuir isotherm is as follows:

$$
\log q e=\log \mathrm{KF}+n \log \mathrm{Ce}
$$

Where qe is the amount of adsorbat adsorbed (mg / $\mathrm{g}$ ), $\mathrm{qm}$ is the adsorbent capacity in adsorption, $\mathrm{KF}$ is Freundlich and $\mathrm{Ce}$ constant is the concentration of adsorbate (mg / L). Where qe is the amount of adsorbed adsorbated ( $\mathrm{mg} / \mathrm{g}$ ), $\mathrm{qm}$ is the adsorbent capacity in adsorption, $\mathrm{KL}$ is Langmuir and $\mathrm{Ce}$ constant is the concentration of adsorbate $(\mathrm{mg} / \mathrm{L})$.

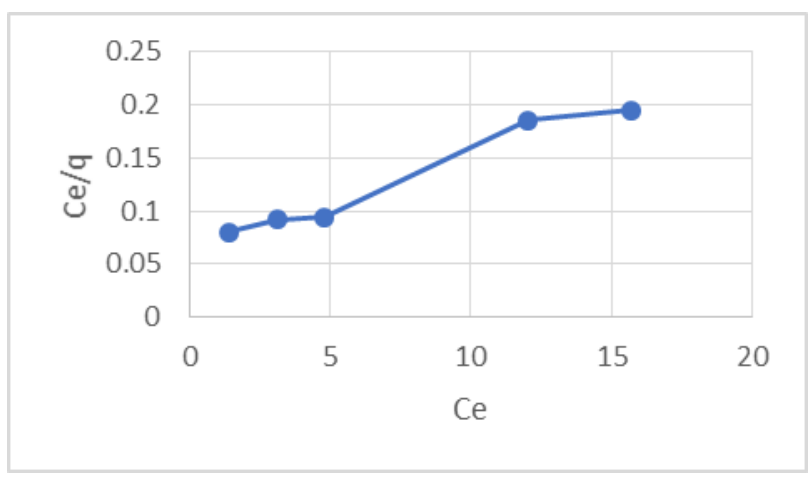

Fig. 6. Langmuir isotherm model.

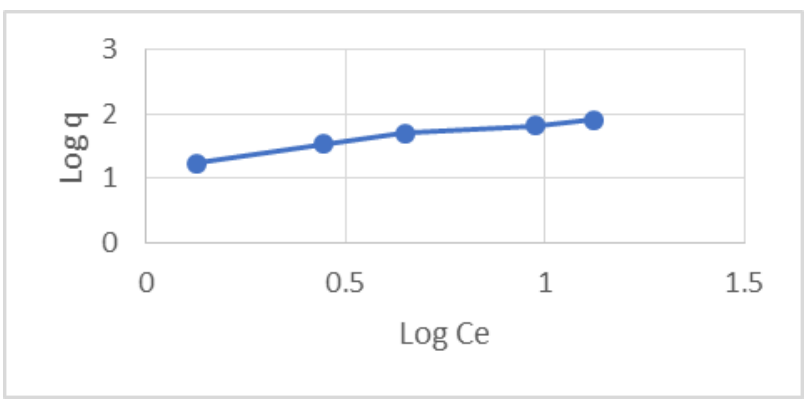

Fig. 7. Freundlich isotherm model.

Figure 6 is a graph of the Langmuir isotherm of silica-APTES. When Ce graphic is made to $\mathrm{Ce} / \mathrm{q}$ it will give the equation of line $y=0.0078 x+0.0614$ with slope 0.0078 and intercept 0.0614 with correlation coefficient $\left(\mathrm{R}^{2}\right)$ equal to 0.9691 .

Freundlich of silica-APTES. When created graph $\log C e$ to $\log \mathrm{q}$ it will give the equation line $\mathrm{y}=$ $0.6539 x+1.2098$ with slope 0.6539 and intercept 1.2098 with correlation coefficient $\left(\mathrm{R}^{2}\right)$ of 0.9595 . Of the two isotherms models, the Langmuir isotherm has a correlation coefficient $\left(\mathrm{R}^{2}\right)$ which is close to 1 compared to the Freundlich isotherm. So it can be said that silicaAPTES more follows the Langmuir isotherm pattern. 


\section{Conclusions}

Based on the research done by APTES modified silica adsorption it is concluded that the APTES modified silica adsorbent has a large adsorption capacity when $\mathrm{pH}$ 8 and the longer the adsorption time. In addition, APTES-modified silica follows a langmuir isotherm pattern in which adsorption occurs chemically by forming a monolayer layer on the surface of the adsorbent.

This research suported by Faculty of Mathematics and Natural Sciences Jakarta State University. We would to thanks Annisa who has helped in the synthesis and characterization of materials.

\section{References}

1. G. Crini, "Non-conventional low-cost adsorbents for dye removal: A review," Bioresour. Technol. 97 (9), 1061-1085 (2006)

2. M.T. Yagub, T.K. Sen, S. Afroze, H.M. Ang, "Dye and its removal from aqueous solution by adsorption: A review," Adv. Colloid Interface Sci. 209, 172-184 (2014)

3. W. Konicki, D. Sibera, E. Mijowska, Z. LendzionBieluń, U. Narkiewicz, "Equilibrium and kinetic studies on acid dye Acid Red 88 adsorption by magnetic ZnFe2O4spinel ferrite nanoparticles," J. Colloid Interface Sci. 398, 152-160 (2013)

4. B.H. Hameed, A.T.M. Din, A.L. Ahmad, "Adsorption of methylene blue onto bamboo-based activated carbon: Kinetics and equilibrium studies," J. Hazard. Mater. 141 (3), 819-825 (2007)

5. A.M. Aljeboree, A.N. Alshirifi, A.F. Alkaim, "Kinetics and equilibrium study for the adsorption of textile dyes on coconut shell activated carbon," Arab. J. Chem. 10, S3381-S3393 (2017)

6. D. Pathania, S. Sharma, P. Singh, "Removal of methylene blue by adsorption onto activated carbon developed from Ficus carica bast," Arab. J. Chem. 10, S1445-S1451 (2017)

7. S. Senthilkumaar, P.R. Varadarajan, K. Porkodi, C.V. Subbhuraam, "Adsorption of methylene blue onto jute fiber carbon: Kinetics and equilibrium studies," J. Colloid Interface Sci. 284 (1), 78-82 (2005)

8. E. Deriu et al. "Probiotic bacteria reduce salmonella typhimurium intestinal colonization by competing for iron," Cell Host Microbe, 14 (1), 26-37 (2013)

9. Y. Ait Ouaissa, M. Chabani, A. Amrane, A. Bensmaili, "Integration of electro coagulation and adsorption for the treatment of tannery wastewater The case of an Algerian factory, Rouiba," Procedia Eng. 33 (2009), 98-101 (2012)

10. S. Sachdeva, A. Kumar, "Preparation of nanoporous composite carbon membrane for separation of rhodamine B dye," J. Memb. Sci. 329 (1-2), 2-10 (2009)
11. T. Santhi, S. Manonmani, V.S. Vasantha, Y.T. Chang, "A new alternative adsorbent for the removal of cationic dyes from aqueous solution," Arab. J. Chem. 9, S466-S474 (2016)

12. K.C. $\mathrm{Ng}$ et al. "Experimental investigation of the silica gel-water adsorption isotherm characteristics," Appl. Therm. Eng. 21 (16), 1631-1642 (2001)

13. S. Guo, H. Xu, F. Zhang, X. Zhu, X. Li, "Preparation and adsorption properties of nano magnetite silica gel for methylene blue from aqueous solution," Colloids Surfaces A Physicochem. Eng. Asp. 546, 244-253 (2018)

14. U. Kalapathy, A. Proctor, J. Shultz, "A simple method for production of pure silica from rice hull ash," Fuel Energy Abstr. 42 (1), 45 (2001)

15. Yusmaniar, A. Purwanto, E.A. Putri, D. Rosyidah, "Adsorption of $\mathrm{Pb}(\mathrm{II})$ using silica gel composite from rice husk ash modified 3aminopropyltriethoxysilane (APTES)-activated carbon from coconut shell," AIP Conf. Proc. 1823 (Ii) (2017)

16. D.D. Asouhidou, K.S. Triantafyllidis, N.K. Lazaridis, K.A. Matis, "Adsorption of Remazol Red 3BS from aqueous solutions using APTES- and cyclodextrin-modified HMS-type mesoporous silicas," Colloids Surfaces A Physicochem. Eng. Asp. 346 (1-3), 83-90 (2009) 